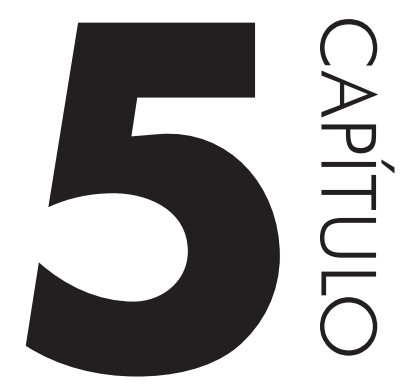

\title{
O PAPEL DA COGNICÃO NOS ESTUDOS FUNCIONALISTAS
}

Maria Angélica Furtado da Cunha

\section{CONSIDERAÇÕES INICIAIS}

Este texto tem por objetivo discutir a atribuição de processos cognitivos em análises linguísticas de natureza funcionalista, mais especificamente, sob o viés da vertente denominada Linguística Funcional Centrada no Uso (LFCU). Essa abordagem resulta da articulação de pressupostos teórico-metodológicos da Linguística Funcional norte-americana à Linguística Cognitiva, em particular, à Gramática de Construções (GOLDBERG, 1995, 2006; CROFT, 2001). No Brasil, a LFCU é adotada pelos pesquisadores do grupo Discurso \& Gramática (CEZARIO; FURTADO DA CUNHA, 2013; FURTADO DA CUNHA, 2015; OLIVEIRA; ROSÁRIO, 2015). 
Essa orientação recente de pesquisas articula-se ao que a literatura inglesa intitula Usage-based Theory (BYBEE, 2010; HOFFMANN; TROUSDALE, 2013). Bybee (2016, p. 303) esclarece que "a teoria baseada no uso se desenvolveu diretamente do funcionalismo norte-americano, praticado por muitas décadas (...), e em certo sentido, é apenas um novo nome para ele".

Esse modelo teórico caracteriza-se, principalmente, pela concepção de língua como uma rede de construções interconectadas em seus diferentes planos por relações de natureza diversa. Nesse sentido, assume-se que a gramática é motivada e regulada por fatores cognitivos, sociocomunicativos e culturais e se reconhece o estatuto fundamental das funções da língua na descrição das suas formas. Decorre dessa compreensão a defesa do estudo da língua com base nesses fatores.

A união da Linguística Funcional à Gramática de Construções implica reconhecer o papel da cognição na emergência e na convencionalização das entidades linguísticas. Nessa linha, uma teoria que tem como ponto de partida dados naturais de uso da língua busca a explicação para os fenômenos linguísticos tanto em aspectos comunicativos, presentes nas situações de interação, como na atuação contínua de processos cognitivos gerais.

\section{BREVE HISTÓRICO}

Tomasello $(1998,2003)$ pode ser apontado como um dos primeiros estudiosos a defender uma visão cognitivo-funcional da língua, sob o rótulo Linguística Cognitivo-Funcional. Sua proposta se justifica com base no fato de que tanto a Linguística Funcional quanto a Linguística Cognitiva rejeitam a autonomia da sintaxe, proclamada pelos gerativistas. Além deste, essas duas correntes compartilham vários pressupostos teórico-metodológicos, como a incorporação da semântica e da pragmática às análises, a não distinção estrita entre léxico e gramática, a relação estreita entre a estrutura das línguas e o uso que os falantes fazem dela nos contextos reais de comunicação, o entendimento de que os dados para a análise linguística são enunciados que ocorrem no discurso natural.

Nessa abordagem integrada, a gramática é entendida como representação cognitiva da experiência do falante com a língua; portanto, ela pode ser afetada pelo uso linguístico. Nessa direção, assume-se que as categorias linguísticas são baseadas na experiência que temos das construções em que elas ocorrem, do mesmo modo que as categorias por meio das quais nós classificamos objetos da natureza e da cultura são baseadas na nossa experiência com o mundo. Assim, a categorização conceptual e a categorização linguística são análogas, ou seja, o conhecimento do mundo e o conhecimento linguístico seguem, essencialmente, os mesmos padrões (TAYLOR, 1998; FURTADO DA CUNHA; OLIVEIRA; MARTELOTTA, 2015). 
De acordo com a visão cognitivo-funcional, as línguas são moldadas pela interação complexa de princípios cognitivos e interacionais que desempenham um papel crucial na mudança linguística, na aquisição e no uso da língua. Como as línguas se assemelham muito no que diz respeito às relações gramaticais que exibem, admite-se que essas semelhanças são o resultado desses princípios cognitivos e funcionais. A língua(gem), portanto, constitui um mosaico complexo de atividades comunicativas, cognitivas e sociais estreitamente integradas a outros aspectos da psicologia humana (TOMASELLO, 1998).

O princípio básico da Linguística Funcional Centrada no Uso consiste no fato de que a estrutura da língua emerge e se fixa à medida que esta é usada (BARLOW; KEMMER, 2000; BYBEE, 2010, 2011). A LFCU entende a aparente regularidade e a instabilidade da língua como motivadas e modeladas pelas práticas discursivas dos usuários no cotidiano social (FURTADO DA CUNHA; TAVARES, 2007). A gramática é, pois, produto da estruturação de aspectos sociocomunicativos e cognitivos da linguagem (BYBEE, 2010). Os usos linguísticos, por sua vez, resultam de modelos convencionalizados com base na interface linguagem, cognição e ambiente sócio-histórico. A inter-relação dessas três dimensões motiva a fixação de padrões gramaticais, via rotinização, com base em ambientes interacionais específicos.

Sendo assim, a LFCU argumenta em favor de uma relação estreita entre a codificação linguística e o uso que os falantes fazem da língua em situações reais de interação comunicativa. Nesse cenário, a língua é concebida como um sistema adaptativo complexo, uma estrutura plástica, constituída, ao mesmo tempo, de padrões mais ou menos regulares e de outros que emergem, em virtude de necessidades cognitivas e/ou comunicativas (GIVÓN, 2001; BYBEE, 2010). O sistema linguístico tem, pois, uma natureza eminentemente dinâmica, já que surge da adaptação das habilidades cognitivas humanas a eventos de comunicação específicos e se desenvolve com base na repetição ou ritualização desses eventos.

Dadas essas assunções, a LFCU busca descrever e explicar os fatos linguísticos com base nas funções (semântico-cognitivas e discursivo-pragmáticas) que desempenham nos diversos contextos de uso da língua, integrando sincronia e diacronia, numa abordagem pancrônica (BYBEE, 2010). Alguns dos fatores considerados nas análises são os efeitos da frequência de uso, a modelagem das estruturas linguísticas no contexto discursivo e as inferências pragmáticas que acompanham a língua na interação. Todos os elementos que compõem o processo que leva ao desenvolvimento de novas entidades linguísticas surgem do uso da língua em contexto e envolvem habilidades e estratégias cognitivas que também são mobilizadas em tarefas não linguísticas. 


\section{LÍNGUA E COGNIÇ̃̃o}

O termo cognição refere-se ao processo neuro-racional de geração do conhecimento humano com base na interação do organismo com o meio. Em outras palavras, diz respeito ao conjunto de operações mentais configuradoras de nosso sistema conceitual, tendo como suporte o contato do indivíduo com o ambiente físico e sociocultural em que vive (IBAÑEZ, 2001; MARTELOTTA; PALOMANES, 2008).

De acordo com Bybee (2010), o objetivo de uma teoria linguística deve ser descrever e explicar as propriedades da estrutura linguística a partir da aplicação de processos cognitivos gerais, os quais operam em outros domínios cognitivos que não a linguagem, como a visão e a música, por exemplo. A emergência da estrutura linguística é, pois, atribuída à aplicação repetida desses processos, sendo a língua concebida como um sistema adaptativo complexo, nos termos de $\mathrm{Du}$ Bois (1985) e Hopper (1987).

Nesse viés, a estruturação linguística emana de processos cognitivos de domínio geral, como nossa capacidade de categorizar, estabelecer relações e operar em níveis locais e globais. Logo, a organização da língua não é intrinsicamente diferente da organização de outros aspectos da cognição.

Diversas pesquisas evidenciam que, de um modo geral, as categorias linguísticas se comportam como as categorias conceituais humanas (THOMPSON; HOPPER, 2001; TAYLOR, 1995; LAKOFF, 1987; LABOV, 1973). A gramática da oração ou estrutura argumental (a relação entre o predicado e seus argumentos), por exemplo, é formada do mesmo modo que as outras categorias: por meio do contínuo processo cognitivo de classificação, refinamento e generalização a partir das interações comunicativas diárias. Como defendem Thompson e Hopper (2001), o sentido de um verbo ou predicado está relacionado aos esquemas léxico-gramaticais em que ele pode ocorrer, e a estrutura argumental é essencialmente um subconjunto desses esquemas. A frequência de uso de uma determinada construção leva a seu estabelecimento no repertório do falante e faz dela uma unidade de processamento, o que implica que o falante explora recursos gramaticais disponíveis para atingir seus objetivos comunicativos. No entanto, o discurso exibe padrões recorrentes que extrapolam o que é previsível pelas regras gramaticais, apenas, e a explicação para a existência desses padrões deve ser procurada no âmbito da cognição e da comunicação.

Entre os processos cognitivos de domínio geral arrolados por Bybee (2010), vou abordar, aqui, categorização e chunking. A categorização é um processo cognitivo de domínio geral no sentido de que categorias perceptuais de vários tipos são criadas com base na experiência humana, independente da língua. No domínio linguístico, a categorização diz respeito à semelhança ou identidade que ocorre quando palavras e sintagmas e suas partes componentes são reconhecidas e associadas a representações armazenadas na mente do falante. As categorias re- 
sultantes são a fundação do sistema linguístico, sejam fonemas, morfemas, itens lexicais, sintagmas ou construções (BYBEE, 2010).

A categorização permeia nossa relação com o mundo físico e social e com nosso intelecto. Entendemos o mundo não apenas em termos de coisas individuais, mas também em termos de categorias de coisas. E isso se dá também no domínio linguístico: do mesmo modo que categorizamos o universo biofísico e sociocultural, categorizamos a língua. Tomemos como exemplo a categoria substantivo. O item menino apresenta as características associadas ao protótipo: é concreto, flexiona em gênero e número, pode ser núcleo de um SN, pode ser precedido de determinante e acompanhado por modificador. Por sua vez, o elemento relevância não exibe algumas dessas propriedades (é abstrato e não flexiona em gênero e número), afastando-se do protótipo.

O processo cognitivo de chunking (agrupamento) é responsável pela formação de estruturas mais complexas a partir de sequências de elementos que frequentemente coocorrem. Do ponto de vista linguístico, essas estruturas correspondem a construções e expressões formulaicas. Sequências repetidas são embaladas juntas em termos cognitivos de modo que a sequência pode ser tomada como uma única unidade (BYBEE, 2010). É o que acontece, por exemplo, com as construções dar nó em pingo d'água, pular corda, acidente fatal, pré-fabricado. A força das relações sequenciais é determinada pela frequência com a qual dois elementos coocorrem, e isso constitui a base cognitiva subjacente para a morfossintaxe e sua organização hierárquica. Tendo como suporte a organização da memória, chunking é um processo que influencia todos os sistemas cognitivos e representa uma propriedade tanto do nível da produção quanto da percepção, contribuindo significativamente para fluência e facilidade do uso da língua. Isso quer dizer que, embora extensa, uma cadeia de palavras pode ser produzida e processada mais facilmente se essas palavras podem ser acessadas em conjunto, devido à frequência de uso.

Cabe observar que categorização e chunking são tomados aqui em dois sentidos próximos, como processos cognitivos e como parâmetros explanatórios. Como processos cognitivos, focalizam motivações para a emergência de novas construções. Assim, dizem respeito à interdependência entre cognição e uso linguístico, buscando explicar como as construções surgem na língua. Como parâmetro explanatório, categorização e chunking são utilizados para explicar o fenômeno linguístico resultante da atuação desses princípios na modelagem da língua ${ }^{1}$.

1 Em referência ao termo gramaticalização, Hopper e Traugott (2003) afirmam que muitos termos na Linguística servem a duas funções: uma é descrever propriedades da língua (fonológicas, morfológicas, sintáticas, por exemplo), a outra é denominar a teoria e o estudo dessas propriedades. 
Outro parâmetro explanatório associado a aspectos cognitivos atuantes no uso da língua é a perspectivação. Relacionada à noção de informatividade ${ }^{2}$, a perspectivação tem a ver com o direcionamento da atenção dos interlocutores sobre uma cena referencial - o evento a ser comunicado - em uma determinada cena atencional - o evento de interação. Em outras palavras, refere-se à focalização de aspectos específicos de uma cena comunicada (TOMASELLO, 1998). Nesse sentido, ao relatar um determinado evento ou descrever uma dada situação, o usuário da língua escolhe um elemento particular como o ponto de vista a partir do qual esse evento ou situação é comunicado. Numa cena comercial de compra e venda, por exemplo, a atenção focal pode ser mapeada no vendedor, com menor atenção no restante, como em "o balconista vendeu o jarro ao floricultor"; ou a atenção pode voltar-se para o comprador, enquanto o restante fica menos saliente em termos cognitivos, como se dá em "O floricultor comprou o jarro ao balconista" (TALMY, 2003). Isso significa que há uma correspondência entre a perspectivação do evento e a formatação da construção que o codifica. Em suma, no uso discursivo da língua, motivações cognitivas, como conceitualização e perspectivação do evento, e interacionais, como status informacional e grau de topicidade do argumento, atuam nas diferentes instanciações da construções de estrutura argumental.

\section{O CONCETTO DE CONSTRUÇÃO}

Formulada no quadro da Linguística Cognitiva, a Gramática de Construções entende que todas as unidades da língua são simbólicas - desde morfemas simples, como o -s de plural, passando por expressões idiomáticas, como olho gordo, estruturas sintáticas, como as construções de estrutura argumental (GOLDBERG, 1995, 2006), até padrões textuais, que se referem ao pareamento tipo (a forma) e gênero (a função) que um texto instancia (ÖSTMAN, 2005). Logo, o conceito de construção dá conta de um grande número de unidades linguísticas, dispostas num continuum, de modo que a distinção entre elas é gradiente e não discreta.

De uma perspectiva sincrônica, o modelo construcionista concebe a língua como sendo constituída de pareamentos de forma-função ${ }^{3}$, ou construções, organizados em uma rede (GOLDBERG, 2006; LANGACKER, 2008).

As construções são entendidas como unidades simbólicas convencionais (LANGACKER, 1987; CROFT, 2005): unidades porque algum aspecto do signo

2 Na Linguística Funcional clássica, informatividade diz respeito à relação entre a codificação de um referente e seu status discursivo-pragmático.

3 Em sua formulação original (GOLDBERG, 1995), a construção é definida como um par forma-significado. Entendo o termo função como equivalente a significado, nos termos deCroft (2001). 
é tão idiossincrático (GOLDBERG, 1995) ou tão frequente (GOLDBERG, 2006) que ele é armazenado como um pareamento de forma-função na mente do usuário da língua; simbólicas porque são signos, associações arbitrárias de forma e significado ${ }^{4}$; e convencionais porque são compartilhadas por um grupo de falantes. Nessa definição, significado compreende propriedades semânticas, pragmáticas e/ou discursivo-funcionais relacionadas a uma determinada configuração estrutural, ou seja, todos os aspectos convencionalizados da função da construção, incluindo as particularidades da situação descrita no enunciado, as propriedades do discurso em que este ocorre e o próprio contexto de uso (CROFT, 2001).

A construção tem significado próprio, esquemático, parcialmente independente das palavras que a compõem, servindo, pois, como um esquema ou modelo que reúne o que é comum a um conjunto de elementos da mesma natureza (GOLDBERG, 1995). Tomasello (2003) se refere à concepção de construções linguísticas como esquemas cognitivos, isto é, procedimentos relativamente automatizados para atingir determinados objetivos comunicativos. Para esse autor, os formatos oracionais são motivados pela cognição humana, por meio do modelo de evento, e pela comunicação, mediante os objetivos e necessidades comunicativas dos interlocutores. A frequência de ocorrência de um dado formato serve para fixá-lo no repertório do falante e torná-lo uma unidade de processamento.

Convém frisar que as construções são esquemas abstratos e convencionais, que se instanciam no uso linguístico por meio de ocorrências específicas. Bybee (2010) defende a ideia de que a maioria das construções é parcialmente esquemática, com posições vazias que podem ser preenchidas com uma categoria de itens semanticamente definidos 5 . Por outro lado, a autora salienta que as construções geralmente têm algumas partes fixas que são cruciais para o estabelecimento do exemplar prototípico. Nesse sentido, pode-se dizer, com Traugott e Trousdale (2013), que a esquematicidade de uma construção linguística diz respeito ao grau em que ela compreende padrões mais gerais através de uma série de construções mais específicas. Assim, as construções de estrutura argumental, organizadas em

4 Croft (2001, p. 18) atenua o peso da arbitrariedade da relação entre forma e função afirmando que esse pareamento pode ser "pelo menos parcialmente arbitrário". Goldberg (2006, p. 203), por sua vez, seguindo funcionalistas como Haiman (1983), Bybee (1985), Givón (1991), admite que "o estreito vínculo semântico entre itens tende a ser representado por forte vínculo sintático correspondente". Tendo em vista a incompatibilidade teórica entre iconicidade, defendida pela Linguística Funcional, e arbitrariedade, os pesquisadores do grupo Discurso \& Gramática consideram a construção como parcialmente arbitrária/motivada (cf. FURTADO DA CUNHA; SILVA; BISPO, 2016).

5 Note-se que construções idiomáticas, como tirar o pai da forca, são totalmente especificadas, sem nenhuma posição vazia a ser preenchida. 
torno de um determinado tipo sintático-semântico de verbo, formam um grupo de construções abstratas, que se relacionam em uma rede construcional.

Já que qualquer elemento formal associado diretamente a alguma função é uma construção, a divisão rígida entre léxico e gramática deixa de existir para a Gramática de Construções assim como para a LFCU. Goldberg (1995) esclarece que a diferença entre construções lexicais e construções sintáticas deve-se ao grau de complexidade interna de cada uma delas, sendo difusa a fronteira entre elas.

Quando falamos, selecionamos itens lexicais e construções armazenados no léxico. Cada um desses elementos contribui com um componente de significado, os quais são fundidos de forma: (i) inteiramente não especificada, dando origem a construções abertas, como as formadas por sujeito e predicado; (ii) lexicalizada em alguma medida, produzindo as construções parcialmente especificadas, como a sequência dar $S N$; e (iii) totalmente especificadas, como a expressão chutar o pau da barraca (FILLMORE, 1985; GOLDBERG, 1995; KAY; FILLMORE, 1999).

Assim como outros sistemas cognitivos, a língua é concebida como uma rede de nós ligados por elos, e as associações entre alguns desses nós tomam a forma de hierarquias de herança. A metáfora de rede reflete o fato de que a língua é um sistema de entidades interconectadas. Segundo Traugott e Trousdale (2013), a ideia de que a língua é uma rede se ajusta às afirmações da Linguística Cognitiva de que outros aspectos da cognição, como a visão e as habilidades musicais, também são estruturados como uma rede. É também coerente com a postura de Bybee (2010) de que a modelagem da língua é parte da nossa capacidade cognitiva de categorizar e estabelecer relações. Por fim, também é consistente com a asserção de Goldberg (1995) de que o conhecimento da língua é parte de um sistema de conhecimento que inclui a visão, a música e outras capacidades cognitivas.

A proposta de rede construcional elaborada por Traugott e Trousdale (2013) contempla um sistema hierárquico organizado em três níveis: os esquemas são generalizações de nível mais alto, mais abstrato; os subesquemas, menos esquemáticos do que os esquemas, estão ligados ao significado central da construção; as microconstruções representam tipos individuais de construção. As microconstruções são instanciadas por construtos (tokens), ocorrências empiricamente atestadas, instâncias de uso em uma ocasião particular, produzidas por um falante particular com um propósito comunicativo particular. A construção ditransitiva em português pode exemplificar essa organização hierárquica. O esquema é representado por $\left(\mathrm{X}_{\text {Agente }}\right.$ causa $\mathrm{Y}_{\text {Recipiente }}$ receber $\left.\mathrm{Z}_{\text {Paciente }}\right)$, com quatro subesquemas que se relacionam ao grau de êxito da transferência de $\mathrm{Z}$ para $\mathrm{Y}$ e envolvem classes de verbos similares. As microconstruções perfilam tipos específicos de verbos para cada subesquema, como dar (sentido central), oferecer, deixar e fazer. Como amostras de construtos ou instanciações dessas microconstruções, temos: eu dou-lhe o 
recibo, você num me oferece esse lugar não?, ela deixou um bilhete pra ele e ela fazia as cartas pra pessoa (FURTADO DA CUNHA, 2015).

\section{CONSTRUCÕ̃ES E PROCESSOS COGNIIIVOS}

Ao analisar a construção ditransitiva no português do Brasil (FURTADO DA CUNHA, 2015), observei que ela pode ser instanciada por dois padrões sintáticos diferentes associados ao mesmo significado central: um em que o objeto indireto (OI) precede o objeto direto (1) e outro em que o objeto direto (OD) antecede o OI (2). Há, então, duas estruturas diferentes codificando o mesmo domínio funcional, a saber, a expressão do significado de um evento de transferência.

(1) ... Quando o paciente e particular, ou seja, a consulta, o mesmo paga a consulta eu dou-lhe o recibo e, em seguida, o paciente se consulta (...) (D\&G/Natal, p. 268)

(2) a. mas aí ele insistiu muito pra ficar ... esses dias com ele ... aí ela disse que cobrava tanto ... se eu num me engano é assim ... que ela cobrava ou então ... depois que ele deu o dinheiro a ela ... mas parece que ela ... cobrou ... (D\&G/Natal, p. 241)

O exame dos dados mostrou que as alternâncias formais envolvidas na ordenação do OI em relação ao OD dizem respeito a diferentes perspectivações da oração ditransitiva. Esses padrões têm a ver, portanto, com a focalização de aspectos específicos de uma cena, motivada pelo ponto de vista a partir do qual o falante escolhe relatar essa situação. Essas alternativas de ordenação podem ser pensadas como a codificação de perspectivas cognitivas diferentes do ato de dar, as quais Tuggy (1998) denomina interação humana e manipulação do objeto. A primeira perspectiva se correlaciona com o recipiente $(\mathrm{OI})$ como objeto primário, enquanto a segunda se correlaciona com a coisa $(\mathrm{OD})$ como objeto primário. Vale ressaltar que no material empírico examinado, em ambas as codificações, a posição preferencial do OI é antes do OD (146 ocorrências no primeiro caso e 104, no segundo).

$\mathrm{Na}$ mesma direção, a pesquisa sobre os padrões de estrutura argumental sintática dos verbos transitivos (FURTADO DA CUNHA, 2011) revelou que o esquema transitivo pode instanciar-se por configurações alternativas, que se desviam do protótipo em algum grau. O padrão estrutural e o esquema conceptual (Sujeito/Agente Verbo/Ação-processo Objeto/Paciente) da oração transitiva prototípica estão diretamente relacionados à expressão do evento transitivo prototípico, em que um agente intencional causa o afetamento ou efetuamento ${ }^{6}$ de um

\footnotetext{
6 Alguns objetos diretos, como o do verbo fazer, são criados pela ação do verbo, e não transformados, como acontece com outros verbos de ação-processo. Hopper (1985) chama esse caso de objeto efetuado, para distingui-lo do objeto afetado.
} 
participante paciente. Assim, um padrão básico de experiência é codificado em um padrão básico da língua.

Uma possibilidade de configuração transitiva se dá com a topicalização do objeto, que ocorre na primeira posição da cláusula, a qual, geralmente, é ocupada pelo sujeito, como em (3):

(3) ... o molho da pizza eu faço com ... é::com alho ... (Corpus D\&G, p. 41, fala)

Nessa amostra, o objeto o molho da pizza é embalado como o referente sobre o qual o procedimento -fazer pizza - é comunicado. Nesse sentido, a perspectivação do objeto reflete alternativas de configuração de um evento com dois participantes por pressões cognitivas e/ou discursivo-pragmáticas. Sendo perspectivado, o objeto dessa oração é promovido à figura na cena transitiva.

A amostra (4) ilustra a atuação do processo cognitivo de chunking:

(4) Eu tive uma crise de garganta muito grande, daquelas, que eu não podia engolir a saliva e nessa fase ele me deu muito apoio e eu pude retribuir quando ele teve catapora, (...). (D\&G/Natal, p. 266, escrita)

$\mathrm{Na}$ oração ditransitiva sublinhada, o sujeito (ele) age intencionalmente de modo que o referente do objeto indireto $(m e)$ "receba" o SN muito apoio, concebido como uma entidade concreta. Temos, aqui, um chunk (BYBEE, 2010), em que $X$ dar apoio a $Y$ se fixou a partir da frequência de uso de dar seguido de apoio. Embora a expressão dar apoio seja relativamente fixa, suas partes internas ainda são identificáveis, o que se evidencia pela possibilidade de acrescentar modificadores entre elas (muito apoio). Cabe observar que as construções com dar, como em (4), em que esse verbo atua como verbo-suporte ou verbo-leve (NEVES, 1996, 2000; TROUSDALE, 2008; CASTILHO, 2010, entre outros) apresentam graus variáveis de idiomaticidade. Nas instanciações da construção com dar SN mais ou menos idiomáticas, resultado do processo de chunking, as funções do verbo e do SN que o segue se alteram, o que leva à reinterpretação da construção como um todo. O verbo se esvazia do seu sentido lexical pleno e passa a concentrar informações gramaticais, como tempo, modo, aspecto, voz e concordância com o sujeito.

\section{CONSIDERAÇÕES FINAIS}

Este texto teve como objetivo abordar a relação entre a Linguística Funcional Centrada no Uso e questões associadas à natureza do conhecimento humano, destacando alguns processos cognitivos de domínio geral. A LFCU acata a existência de processos cognitivos que respondem pela criação dos significados nas situações reais de comunicação, limitando sua variabilidade. Ao mesmo tempo, 
admite fortemente a atuação de fatores de natureza social na configuração e fixação da língua. A abordagem cognitivo-funcional concebe a língua(gem) como um dispositivo para a construção do conhecimento: ela é um instrumento cognitivo que aciona um conjunto de princípios relativamente limitados, que operam sobre os conhecimentos armazenados na memória ou presentes na situação comunicativa (SALOMÃO, 1999). Nessa linha, a língua não constitui um órgão mental autônomo, mas um conjunto complexo de atividades comunicativas, sociais e cognitivas. Sua estrutura, longe de ser um conhecimento fechado em si mesmo, constitui o reflexo de processos gerais de pensamento que os indivíduos elaboram ao criarem significados, adaptando-os a diferentes situações de interação com outros indivíduos. Nessa visão, a hipótese de que as circunstâncias de uso impactam a representação cognitiva da língua é fundamental.

Seguindo Bybee (2010), a Linguística (Funcional) Centrada no Uso busca relacionar padrões que se manifestam na língua em uso à atuação de processos cognitivos de domínio geral, conforme a proposição teórica de que padrões de uso frequentes correspondem a estruturas gramaticais comuns translinguisticamente. Essa orientação analítica torna possível o tratamento tanto de exemplares sincrônicos como de tipos de mudança linguística, a fim de explicar a diversidade de estruturas dentro de uma mesma língua ou entre línguas diferentes. Além desses processos cognitivos, fatores socioculturais devem ser levados em consideração quando se procura investigar a emergência de novos modelos estruturais e semânticos na língua.

Para Kay (2005), a flexibilidade tanto na codificação quanto na conceitualização é a principal razão por que a gramática parece arbitrária. Conceitualmente, há incontáveis maneiras de conceber um dado evento, e uma concepção particular de um evento pode se desviar do cânone em qualquer grau. Linguisticamente, uma variedade de recursos gramaticais, cada um com valores múltiplos agrupados em torno de um protótipo, está disponível como meio alternativo de codificar uma dada concepção. As propriedades objetivas de um evento são consequentemente insuficientes para predizer a estrutura gramatical de uma oração que o descreve.

No que diz respeito às construções, os falantes armazenam instanciações de construções com base em enunciados e seus significados usados em uma determinada situação de interação. O processo cognitivo conhecido como memória enriquecida (BYBEE, 2010) se refere exatamente à estocagem mental de detalhes da experiência com a língua. Esse processo inclui, além de detalhes fonéticos para palavras e sintagmas, contextos de uso, significados e inferências associadas a enunciados. O conhecimento gramatical é, pois, formado a partir de generalizações que levam em conta padrões de uso. 


\section{REFERÊNCIAS BIBLIOGRÁFICAS}

BARLOW, M. KEMMER, S. (Eds.). Usage based models of language. Chicago: UCP, 2000. BYBEE, J. Morphology: a study of there lation between me aningand form. Amsterdam: John Benjamins, 1985.

. Language, usageandcognition. Cambridge: CUP, 2010.

. Usage-based theory and grammaticalization. In: NARROG, H.; HEINE, B. (Eds.). The Oxford handbook of grammaticalization. Oxford: OUP, 2011, p. 69-78.

. Lingua, uso e cognição. Tradução de Maria Angélica Furtado da Cunha. São Paulo: Cortez, 2016.

CASTILHO, A. T. Gramática do português brasileiro. São Paulo: Contexto, 2010.

CEZARIO, M. M.; FURTADO DA CUNHA, M. A.; (Org.). Linguística centrada no uso: uma homenagem a Mário Martelotta. Rio de Janeiro: Mauad X/FAPERJ, 2013.

CROFT, W. Radical construction grammar: syntactic theory in typological perspective. Oxford: OUP, 2001.

. Logical and typological arguments for radical construction grammar. In: ÖSTMAN, J-O; FRIED, M. (Eds.). Construction grammars: cognitive grounding and theoretical extension. Amsterdam: John Benjamins, 2005.

DU BOIS, J. W. Competingmotivations. In: HAIMAN, J. (Ed.). Iconicity in syntax. Amsterdam: John Benjamins, 1985.

FILLMORE, C. J. Frames and the semantics of understanding. Quaderni di Semantica, v. 6, n. 2, p. 222-255, 1985.

FURTADO DA CUNHA, M. A. A construção transitiva no português do Brasil. Actas del XVI Congreso Internacional de la ALFAL, 2011, p. 3645-3654.

. O estatuto argumental do objeto indireto e a construção ditransitiva no português do Brasil. In: FURTADO DA CUNHA, M. A. (Org.). A gramática da oração - diferentes olhares. Natal: EDUFRN, 2015, p. 135-165.

FURTADO DA CUNHA, M. A.; TAVARES, M. A. Funcionalismo e ensino de gramática. Natal: EDUFRN, 2007.

FURTADO DA CUNHA, M. A.; OLIVEIRA, M. R.; MARTELOTTA, M. E. (Org.). Linguística funcional: teoria e prática. São Paulo: Parábola, 2015.

FURTADO DA CUNHA, M. A.; SILVA, J. R.; BISPO, E. B. O pareamento forma-função nas construções: questões teóricas e operacionais. Revista Linguística, número especial, p. 55-67, 2016.

GIVÓN, T. Isomorphism in the grammatical code: cognitive and biological considerations. Studies in Language, v. 1, p. 85-114, 1991. 
. Syntax: an introduction, v. 1. Amsterdam: John Benjamins, 2001.

GOLDBERG, A. E. Constructions: a construction grammar approach to argument structure. Chicago: CUP, 1995.

. Constructions at work: the nature of generalization in language. Oxford: OUP, 2006.

HAIMAN, J. Iconic and economic motivation. Language v. 59, p. 781-819, 1983.

HOFFMANN, T.; TROUSDALE, G. (Eds.). The Oxford handbook of construction grammar. Oxford: OUP, 2013.

HOPPER, P. J. Causes and affects. CLS, v. 21, p. 67-88, 1985.

. Emergent grammar. Berkeley linguistics society, v. 13, p. 139-157, 1987.

IBAÑEZ, F. J. R. de M. Linguística cognitiva: semântica, pragmática y construcciones. Círculo de linguísticaaplicada a la comunicación. Universidad de La Rioja, 2001.

KAY, P. Argument structure construction sand the argument-adjunct distinction. In: Fried, M.; BOAS, H. (Eds.). Grammatical constructions: backtothe roots. Amsterdam: John Benjamins, 2005, p. 71-98.

KAY, P.; FILLMORE, C. J. Grammatical constructions and linguistic generalizations: the what's $\mathrm{x}$ doing $\mathrm{y}$ ? Construction. Language, v. 75, p. 1-33, 1999.

LABOV, W. Sociolinguistic patterns. Pennsylvania: UPP, 1973.

LAKOFF, G. Women, fire and dangerous things: what categories reveal about the mind. Chicago: UCP, 1987.

LANGACKER, R. W. Foundations of cognitive grammar: theoretical prerequisites. v. 1. Stanford: SUP, 1987.

. Cognitive Grammar: a basic Introduction. New York: OUP, 2008.

MARTELOTTA, M. E.; PALOMANES, R. Linguísticacognitiva. In: MARTELOTTA, M. E. (Org.). Manual de linguística. São Paulo: Contexto, 2008, p. 177-192.

NEVES, M. H. de M. Estudo das construções com verbo-suporte em português. In: KOCH, I. G. V. (Org.). Gramática do português falado, V. VI: Desenvolvimentos. Campinas: Editora da Unicamp/Fapesp, 1996, p. 201-230.

. Gramática de usos do português. São Paulo: Unesp, 2000.

OLIVEIRA, M. R. de; ROSÁRIO, I. da C. do (Org.). Linguística centrada no uso: teoria e método. Rio de Janeiro: Lamparina/FAPERJ, 2015.

ÖSTMAN, J. Construction discourse: a prolegomenon. In: ÖSTMAN, J.; FRIED, M. (Eds.). Construction grammars: cognitive grounding and theoretical extensions. Amsterdam: John Benjamins, 2005, p. 121-144.

SALOMÃO, M. M. A questão da construção do sentido e a revisão da agenda dos estudos da linguagem. Veredas, v. 4, n. 1, p. 61-79, 1999. 
TALMY, L. Toward to a cognitive semantics: concepts structuring systems. v. 1. Cambridge: MIT Press, 2003.

TAYLOR, J. R. Linguistic categorization. 2. ed. Oxford: OUP, 1995.

Syntactic construction as prototype categories. In: TOMASELLO, M. (Ed.). The new psychology of language. v. 1. London: LEA, 1998.

THOMPSON, S. A.; HOPPER, P.J. Transitivity, clause structure, and argument structure: evidence from conversation. In: J. BYBEE, J.; HOPPER, P. (Eds.). Frequency and the emergence of linguistic structure. Amsterdam: John Benjamins, 2001, p. 27-60.

TOMASELLO, M. (Ed.). The new psychology of language: cognitive and functional approaches to language structure. v. 1. London: LEA, 1998.

(Ed.). The new psychology of language: cognitive and functional approaches to language structure. v. 2. London: LEA. 2003.

TROUSDALE, G. Constructions in grammaticalizationandlexicalization: Evidencefromthehistoryof a compositepredicateconstruction in English. In: TROUSDALE, G.; GISBORNE, N. (Eds.). Constructional approaches toEnglishgrammar. BerlIn: Mouton de Gruyter, 2008.

TRAUGOTT, E. C.; TROUSDALE, G. Constructionalization and constructional changes. Oxford: OUP, 2013.

TUGGY, D. Giving in Nawatl. In: NEWMAN, J. (Ed.). The linguisticsofgiving. TypologicalStudies in Language, v. 36. Amsterdam: John Benjamins, 1998, p. 35-65. 